\title{
Is There an Association between Variceal Bleed and Helicobacter pylori Infection in Cirrhotic Patients with Portal Hypertension? A prospective cohort study
}

Sathyanarayan Varuna, ${ }^{1}$ Sathasivam Sureshkumar, ${ }^{1}$ Balakrishnan Gurushankari, ${ }^{1}$ Elangovan Archana, ${ }^{1}$ Subair Mohsina, ${ }^{1}$ "Vikram Kate, ${ }^{1}$ Vairappan Balasubramanian, ${ }^{2}$ Thulasingam Mahalakshmy ${ }^{3}$

\begin{abstract}
Objectives: This study aimed to determine the association between Helicobacter pylori infection and variceal bleeding as well as rebleeding in cases of cirrhosis with portal hypertension. Methods: This prospective cohort study included patients with bleeding oesophageal varices and was conducted at the Department of Surgery, Jawaharlal Institute of Postgraduate Medical Education and Research, Pondicherry, India, from August 2016 to July 2018. Results: A total of 190 patients were assessed for eligibility, of which 159 patients were included in this study. Among the 159 patients, 124 (78.0\%) had alcohol-related liver disease and eight had hepatitis B virus-related liver disease. Seven patients with varices had bled neither at presentation nor during the follow-up period. A total of 78 (49.1\%) patients were $H$. pylori infected. The primary outcome, which was correlation between prevalence of $H$. pylori and the incidence of bleeding/rebleeding from varices as well as encephalopathy found that patients with oesophageal varices (adjusted risk $[\mathrm{AR}]=0.714)$ and $\mathrm{H}$. pylori infection $(\mathrm{AR}=0.682)$ had a lower risk of variceal rebleeding. Among H. pylori-negative patients, pepsinogen I was higher in patients with rebleeding ( 30.7 versus $14.4 \mathrm{ng} / \mathrm{mL} ; P<0.001$ ). The secondary outcome, which was correlation of the site of bleeding with $H$. pylori infection and the association of the ratio of pepsinogen I/II with bleeding showed that among $H$. pylori-positive patients, the ratio of pepsinogen I/II was higher in patients with rebleeding ( 2.9 versus $1.3 \mathrm{ng} / \mathrm{mL} ; P=0.023)$. Conclusion: $H$. pylori infection was associated with a lower risk of rebleeding in cases of cirrhosis with portal hypertension. Irrespective of the status of the $H$. pylori infection, rebleeding was associated with increased levels of gastric acid output, as demonstrated by the level of pepsinogen.
\end{abstract}

Keywords: Pepsinogen; Hepatic Encephalopathy; Gastric Acid; Helicobacter Pylori; India.
ADVANCES IN KNOWLEDGE
This study found that rebleeding episodes in patients with oesophageal varices were significantly less in cases with Helicobacter pylori infection.
A comparison between the oesophageal and gastric varices found that the risk of rebleeding was higher in the latter.
Child-Pugh class B and C patients were documented as having a higher risk of rebleeding.
Pepsinogen levels are also directly correlated with the risk of rebleeding; higher levels were associated with an increased risk of rebleeding.

\section{Application to Patient Care}

The findings of the present study suggest that the routine eradication of H. pylori infection might not be necessary for patients with bleeding oesophageal varices, as the presence of H. pylori infection is found to be associated with a lower risk of rebleeding.

Higher pepsinogen levels are associated with increased acid output, which in turn is associated with an increased risk of rebleeding; thus it can be postulated that acid reduction measures may be necessary to reduce the risk of rebleeding.

\section{$H$} EICOBACTER PYLORI INFECTION IS A universal bacterial infection that remains a common cause of morbidity and mortality. ${ }^{1-3}$ It is now known that $H$. pylori infection is associated not only with chronic gastritis and peptic ulcer disease but also with mucosa-associated lymphoid tissue lymphoma and gastric adenocarcinoma. ${ }^{2}$ Bleeding from varices is one of the most common causes of upper gastrointestinal (UGI) bleeding and is at times fatal in patients with liver cirrhosis. ${ }^{4}$ Oesophageal varices cause the oesophagogastric junction patulous to increase acid reflux into the oesophagus, thus increasing the risk of bleeding. ${ }^{5}$ The prevalence of $H$. pylori infection is significantly less in patients with gastro-oesophageal reflux disease (GERD) compared to those without GERD, indicating a possible low acid output with H. pylori. In Sakamoto et al.'s prospective analysis, they proposed a possible negative correlation between variceal bleeding and rebleeding and $H$. pylori infection due to a possible reduction in the gastric acid output. ${ }^{4}$ However, the proposed negative association has not been clearly established. 
Serum pepsinogen is an indirect marker of gastric acid output. It helps in quantifying the gastric acid output and establishing the gastric mucosal atrophy caused by $H$. pylori. In $H$. pylori-negative patients, pepsinogen (PG) I correlates with the maximal acid output, whereas in $H$. pylori-positive cases, a ratio of PG I and II correlates better with the maximal gastric acid output. ${ }^{5}$ On analysis of the results, the authors reported a direct correlation of PG I and PG I/II ratio with acid secretion irrespective of $H$. pylori status, whereas there was no direct correlation between PG II and acid secretion. ${ }^{5} \mathrm{H}$. pylori, being an ammoniaproducing organism, may increase the incidence of hepatic encephalopathy in patients with cirrhosis. ${ }^{5,6} \mathrm{~A}$ few reports have recommended eradication therapy, suggesting that $H$. pylori increases the incidence of hepatic encephalopathy. ${ }^{5,6}$ Considering the possible negative association of $H$. pylori infection with the incidence of rebleeding, $H$. pylori eradication to prevent the risk of hepatic encephalopathy needs to be considered with utmost caution. The current study was carried out to determine the role of $H$. pylori infection in reducing variceal bleeding and rebleeding in patients with cirrhosis and portal hypertension.

\section{Methods}

This prospective cohort study was conducted at the Department of Surgery, Jawaharlal Institute of Postgraduate Medical Education and Research (JIPMER), Pondicherry, India, from August 2016 to July 2018. All patients with a diagnosis of bleeding oesophageal varices during the study's period were included. Patients with non-variceal causes of UGI bleeding; patients on drugs that reduce acid output, such as proton pump inhibitors (PPI), in the six weeks preceding the study; and patients who had received $H$. pylori eradication in the preceding three months were excluded from the study.

Cirrhosis and portal hypertension were diagnosed using ultrasonography and upper gastrointestinal endoscopy (UGIE), respectively. Liver cirrhosis was diagnosed by the presence of altered liver echoes on ultrasonography. ${ }^{7}$ The presence of oesophageal or gastric varices was taken as an indicator of portal hypertension. During endoscopy, biopsies for $H$. pylori diagnosis were performed at four different sites of the stomach-two at the antrum and two at the corpus. ${ }^{8}$ One biopsy each from the corpus and antrum was used for rapid urease testing for H. pylori, which was conducted with a solution prepared and standardised at the authors' institute. The second set of biopsies from the corpus and antrum was sent for histopathological examination of $H$. pylori using Giemsa stain. If fresh or altered blood was found in the stomach, biopsies were performed during subsequent follow-up endoscopy, as the presence of blood in the stomach is known to affect the results of $H$. pylori testing. ${ }^{9,10}$ Patients were considered positive for $H$. pylori infection if either the urease or histopathology was positive or both were positive. Patients were considered negative for $H$. pylori only if both the tests were negative. Endoscopic variceal band ligation or sclerotherapy was done as per the standard protocol. Approximately $5 \mathrm{~mL}$ of blood was collected from the patients in a fasting state by venepuncture and the serum was separated by centrifugation. The samples were labelled and stored at $-20^{\circ} \mathrm{C}$. The samples were analysed for serum PG I and II levels using separate enzyme-linked immunosorbent assay kits for each of the subtypes (Ray Biotech Inc., Peachtree Corners, Georgia, USA). ${ }^{11}$ Bleeding/rebleeding was defined as either haematemesis or melena or both. ${ }^{4}$ Hepatic encephalopathy was diagnosed based on the presence of clinical symptoms, including loss of orientation to time and place, agitation, the presence of asterixis, stupor or coma, the improvement of these features with standard treatment for hepatic encephalopathy and the absence of any other cause of neurological impairment in the patient's history and also during follow-up. ${ }^{12}$ Portal hypertensive gastropathy (PHG) was defined as changes in the mucosa of the stomach in patients with portal hypertension. ${ }^{13}$ The changes included friability of the gastric mucosa and the presence of ecstatic vessels that had a mosaic pattern in endoscopy. Patients were followed-up for bleeding/ rebleeding, incidence and development of hepatic encephalopathy at three-month intervals up to nine months, till the end of the study or till the patient's death, whichever occurred first.

The primary outcome measures were the prevalence of $H$. pylori infection in patients with oesophageal/gastric/gastro-oesophageal varices due to liver cirrhosis with portal hypertension and the correlation of $H$. pylori infection with the incidence of bleeding/rebleeding from varices and with encephalopathy. The secondary outcome measures included the correlation of the site of bleeding with H. pylori infection and the determination of the association of PG I and PG II and PG I/II ratio with variceal bleeding and $H$. pylori infection.

Data regarding various demographic and clinicopathologic variables were recorded at the time of enrolment, which included age, gender, ultrasonography of the abdomen, findings at UGIE, grade of varices, site of varices and Child-Pugh 
Table 1: Factors predicting variceal rebleeding on univariate analysis $(\mathrm{N}=152)$

\begin{tabular}{|c|c|c|c|c|c|}
\hline \multirow{2}{*}{ Characteristic } & \multirow[t]{2}{*}{ Total } & \multicolumn{2}{|c|}{ n (\%) } & \multirow[t]{2}{*}{ RR $(95 \%$ CI) } & \multirow[t]{2}{*}{$P$ value } \\
\hline & & Rebleed present & No rebleed & & \\
\hline Total & 152 & $58(38.2)$ & $94(61.8)$ & & \\
\hline Male & 121 & $51(42.1)$ & $70(57.9)$ & $1.86(0.9-3.7)$ & 0.045 \\
\hline Female & 31 & $7(22.6)$ & $24(77.4)$ & Ref & \\
\hline Alcohol-induced cirrhosis & 118 & $50(42.4)$ & $68(57.6)$ & $1.80(0.9-3.4)$ & 0.073 \\
\hline Non-alcohol induced cirrhosis & 34 & $8(23.5)$ & $26(76.5)$ & Ref & \\
\hline Oesophageal varices & 127 & $44(34.6)$ & $83(65.4)$ & Ref & \\
\hline Gastric varices & 25 & $14(56.0)$ & $11(44.0)$ & $1.61(1.1-2.5)$ & 0.045 \\
\hline Grade $1 / 2$ oesophageal varices & 93 & $31(33.3)$ & $62(66.7)$ & Ref & \\
\hline Grade 3/4 oesophageal varices & 59 & $27(45.8)$ & $32(54.2)$ & $1.38(0.9-2.1)$ & 0.124 \\
\hline No PHG & 70 & $28(40.0)$ & $42(60.0)$ & $1.13(0.6-1.9)$ & 0.892 \\
\hline Mild PHG & 48 & $18(37.5)$ & $30(62.5)$ & $1.06(0.6-1.9)$ & \\
\hline Severe PHG & 34 & $12(35.3)$ & $22(64.7)$ & Ref & \\
\hline H. pylori positive & 73 & $20(27.4)$ & $53(72.6)$ & Ref & \\
\hline H. pylori negative & 79 & $38(48.1)$ & $41(51.9)$ & $1.75(1.1-2.7)$ & 0.009 \\
\hline Child-Pugh's class A & 43 & $3(7.0)$ & $40(93.0)$ & Ref & \\
\hline Child-Pugh's class B & 82 & $42(51.2)$ & $40(48.8)$ & $7.31(2.4-22.3)$ & $<0.001$ \\
\hline Child-Pugh's class C & 27 & $13(48.1)$ & $14(51.9)$ & $6.87(2.2-22.0)$ & \\
\hline
\end{tabular}

$R R=$ relative risk; $C I=$ confidence interval; $R e f=$ reference; $P H G=$ portal hypertensive gastropathy; $H .=$ Helicobacter *Using Chi-squared test.

Table 2: Multivariate logistic regression showing factors predicting variceal rebleeding.

$\begin{array}{lcc}\text { Variable } & \begin{array}{c}\text { AR } \\ (\mathbf{9 5} \mathbf{C I})\end{array} & \boldsymbol{P}^{\text {value* }} \\ \text { Male gender } & 1.079 & \\ & (0.296-3.941) & 0.908 \\ \text { Alcoholic cirrhosis } & 1.276 & 0.692 \\ & (0.381-4.272) & \\ \text { Oesophageal varices } & 0.714 & 0.009 \\ & (0.555-0.920) & \\ \text { Grade 3/4 varices } & 1.366 & 0.040 \\ & (1.015-1.840) & \\ \text { Positive H. pylori } & 0.682 & 0.046 \\ & (0.469-0.993) & \\ \text { Child-Pugh's class B } & 6.435 & 0.001 \\ & (2.131-19.432) & \\ \text { Child-Pugh's class C } & 4.814 & 0.008 \\ & (1.520-15.254) & \end{array}$

"Dependent variable was the presence or absence of rebleeding. $A R=$ adjusted risk; $C I=$ confidence interval; $H .=$ Helicobacter .

score at presentation. Considering the prevalence of $H$. pylori infection in variceal bleeding patients to be $34.9-52 \%$, with an alpha error of $5 \%$, and the power of the study to be $80 \%$, the sample size was calculated to be $150 ., 13,14$ Considering a $10 \%$ dropout rate, a sample size of 165 was determined for the study. The sample size was calculated using OPENEPI ${ }^{\circledR}$ software (www.openepi.com) for Windows 8 (Microsoft Corp., Redmond, Washington, USA).

Statistical analysis was done using the Statistical Package for the Social Sciences (SPSS), Version 19.0 (IBM Corp., Chicago, Illinois, USA). Numerical data such as serum pepsinogen levels and pepsinogen ratios were expressed in the form of medians (interquartile range); categorical data such as gender, aetiology of cirrhosis, location of bleeding varices, portal gastropathy and the Child-Pugh class were expressed in the form of proportions. Numerical data were analysed using the Mann-Whitney U test or the Kruskal-Wallis test, and categorical data were analysed using a Chi-squared test or Fisher's exact test. A $P$ value of less than 0.05 was considered statistically significant.

This study was approved by the Institute Ethics Committee of JIPMER prior to the commencement of the study (JIP/IEC/2016/27/885). Participants were included in the study after obtaining written, informed consent, and they were allowed the freedom 
Table 3: Correlation of various factors with Helicobacter pylori infection

\begin{tabular}{|c|c|c|c|c|}
\hline \multirow[t]{2}{*}{ Characteristic } & \multirow[t]{2}{*}{ Total } & \multicolumn{2}{|c|}{ n (\%) } & \multirow{2}{*}{$\begin{array}{c}P \\
\text { value }^{*}\end{array}$} \\
\hline & & $\begin{array}{c}H . \\
\text { pylori } \\
\text { present }\end{array}$ & $\begin{array}{c}H . \\
\text { pylori } \\
\text { absent }\end{array}$ & \\
\hline Total & 159 & $\begin{array}{c}78 \\
(49.1)\end{array}$ & $\begin{array}{c}81 \\
(50.9)\end{array}$ & \\
\hline Male & 127 & $\begin{array}{c}62 \\
(48.8)\end{array}$ & $65(51.2)$ & 0.905 \\
\hline Female & 32 & $\begin{array}{c}16 \\
(50.0)\end{array}$ & $\begin{array}{c}16 \\
(50.0)\end{array}$ & \\
\hline $\begin{array}{l}\text { Alcohol- } \\
\text { induced } \\
\text { cirrhosis }\end{array}$ & 124 & $\begin{array}{c}59 \\
(47.6)\end{array}$ & $65(52.4)$ & 0.62 \\
\hline $\begin{array}{l}\text { Non-alcohol } \\
\text { induced } \\
\text { cirrhosis }\end{array}$ & 35 & $\begin{array}{c}19 \\
(54.3)\end{array}$ & $\begin{array}{c}16 \\
(45.7)\end{array}$ & \\
\hline $\begin{array}{l}\text { Oesophageal } \\
\text { varices }\end{array}$ & 133 & $\begin{array}{c}68 \\
(51.1)\end{array}$ & $\begin{array}{c}65 \\
(48.9)\end{array}$ & 0.237 \\
\hline Gastric varices & 26 & $\begin{array}{c}10 \\
(38.5)\end{array}$ & $\begin{array}{c}16 \\
(61.5)\end{array}$ & \\
\hline $\begin{array}{l}\text { Grade } 1 / 2 \\
\text { oesophageal } \\
\text { varices }\end{array}$ & 100 & $\begin{array}{c}52 \\
(52.0)\end{array}$ & $\begin{array}{c}48 \\
(48.0)\end{array}$ & 0.334 \\
\hline $\begin{array}{l}\text { Grade 3/4 } \\
\text { oesophageal } \\
\text { varices }\end{array}$ & 59 & $\begin{array}{c}26 \\
(44.1)\end{array}$ & $\begin{array}{c}33 \\
(55.9)\end{array}$ & \\
\hline No PHG & 75 & $\begin{array}{c}40 \\
(53.3)\end{array}$ & $\begin{array}{c}35 \\
(46.7)\end{array}$ & 0.223 \\
\hline Mild PHG & 49 & $\begin{array}{c}19 \\
(38.8)\end{array}$ & $\begin{array}{c}30 \\
(61.2)\end{array}$ & \\
\hline Severe PHG & 35 & $\begin{array}{c}19 \\
(54.3)\end{array}$ & $\begin{array}{c}16 \\
(45.7)\end{array}$ & \\
\hline $\begin{array}{l}\text { Child-Pugh's } \\
\text { class A }\end{array}$ & 48 & $\begin{array}{c}31 \\
(64.6)\end{array}$ & $\begin{array}{c}17 \\
(35.4)\end{array}$ & 0.026 \\
\hline $\begin{array}{l}\text { Child-Pugh's } \\
\text { class B }\end{array}$ & 83 & $\begin{array}{c}37 \\
(44.6)\end{array}$ & $\begin{array}{c}46 \\
(55.4)\end{array}$ & \\
\hline $\begin{array}{l}\text { Child-Pugh's } \\
\text { class C }\end{array}$ & 28 & $\begin{array}{c}10 \\
(35.7)\end{array}$ & $\begin{array}{c}18 \\
(64.3)\end{array}$ & \\
\hline
\end{tabular}

to withdraw at any point of time during the study. All the provisions of the Declaration of Helsinki were followed in the study. The study was registered at www.ctri.gov.in (Clinical Trials Registry-India ref no: CTRI/2018/04/013357).

\section{Results}

A total of 190 patients were assessed for eligibility during the study period; some patients were excluded and a final sample size of 159 patients were included in the study. The total number of males and females was 127 and 32, respectively. Overall, 124 patients (78.0\%)

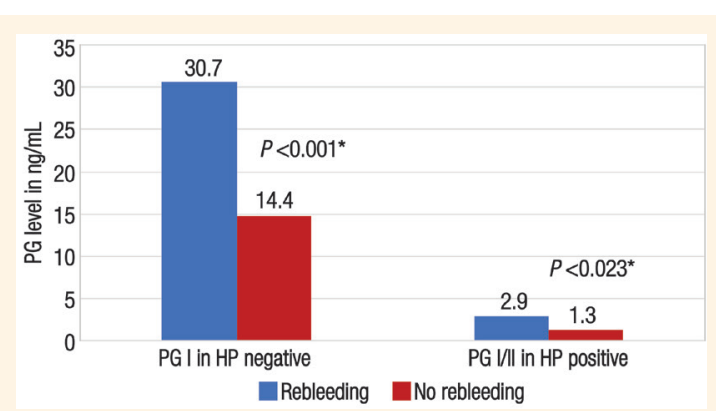

Figure 1: Comparison of pepsinogen I and pepsinogen I/II ratio between patients with rebleeding and those without it.

$H P=$ Helicobacter pylori .

"Using Kruskal-Wallis test.

had alcohol-related liver disease, eight patients had hepatitis B virus-related liver disease and only one patient had hepatitis $\mathrm{C}$ virus-related liver disease. The aetiology of cirrhosis in 26 patients (16.4\%) was not known (idiopathic). In total, 30 patients were lost to follow-up, and 11 patients died during the course of the study. The median follow-up period was nine months. Seven patients with varices had bled neither at presentation nor during the follow-up period. Therefore, the analysis was carried out with 152 patients. On univariate analysis, male gender (relative risk $[\mathrm{RR}]=1.86 ; P=0.045)$, gastric varices $(\mathrm{RR}=1.61$; $P=0.045), H$. pylori-negative status $(\mathrm{RR}=1.75 ; P=$ $0.009)$ and Child-Pugh class B and $C(P=0.001)$ were found to be significantly associated with rebleeding episodes [Table 1].

The prevalence of $H$. pylori infection among cirrhotic patients with portal hypertension was found to be $49.1 \%$. Patients with $H$. pylori infection were found to have less rebleeding episodes than those without it (adjusted risk [AR] $=0.682,95 \%$ confidence interval $[\mathrm{CI}]=0.469-0.993 ; P=0.046)$. Patients belonging to Child-Pugh class $\mathrm{B}(\mathrm{AR}=6.435,95 \% \mathrm{CI}$ $=2.131-19.432 ; P=0.001)$ and Child-Pugh class $C$ $(\mathrm{AR}=4.814,95 \% \mathrm{CI}=1.520-15.254 ; P=0.008)$ had higher rebleeding episodes compared to patients in Child-Pugh class A [Table 2].

A total of seven out of 11 patients who had encephalopathy were $H$. pylori infected $(\mathrm{RR}=1.83)$; however, this difference was not statistically significant $(P=0.363)$. The site of variceal bleeding in patients was independent of $H$. pylori status $(P=0.237)$ [Table 3]. Among patients negative for $H$. pylori infection, rebleeding was significantly associated with higher levels of PG I (30.7 versus $14.4 \mathrm{ng} / \mathrm{mL} ; P<0.001)$. Among patients positive for $H$. pylori infection, rebleeding was associated with a higher ratio of PG I/ II (2.9 versus $1.3 \mathrm{ng} / \mathrm{mL} ; P=0.023$ ) [Figure 1]. 


\section{Discussion}

The presence of $H$. pylori was considered a topic of interest for the present study because some researchers have postulated that mucosal inflammation resulting from $H$. pylori infection might weaken the mucosa and may trigger bleeding from varices. In contrast, others have suggested that by causing atrophic gastritis and reducing acid output from the stomach, it might reduce variceal bleeding episodes. ${ }^{4,5}$

In the present study, the prevalence of $H$. pylori infection among cirrhotic patients with portal hypertension was 49.1\%. Many studies have been published on the prevalence of $H$. pylori infection and its association with cirrhosis and portal hypertension, albeit with conflicting results. ${ }^{15-18}$ While some studies have found that $H$. pylori infection is more prevalent among cirrhotic patients compared to the general population, others have found no such difference. Previous studies have shown the prevalence of $H$. pylori infection in a similar population to be $67-83.3 \% .^{15,16}$ The present study found that the prevalence of $H$. pylori infection was lower among cirrhotic patients compared to the general population. Previous studies have shown that viral cirrhotic patients have a higher prevalence of $H$. pylori infection than those with other aetiologies of cirrhosis. ${ }^{19,20}$ However, in the present study, the majority of the patients had alcohol-induced cirrhosis (78.0\%) with associated PHG (52.8\%), which probably accounted for the lower prevalence of $H$. pylori, as studies have shown that PHG does not favour $H$. pylori colonisation. ${ }^{13}$ In the present study, as expected, patients belonging to Child-Pugh class $B$ and $C$ had higher rebleeding episodes compared to Child-Pugh class A; this can act as a confounding factor when correlating with $H$. pylori. However, multivariate analysis revealed $H$. pylori infection to be a protective factor.

In the present study, H. pylori infected patients were found to have lesser rebleeding episodes than those patients without it $(\mathrm{AR}=0.682,95 \% \mathrm{CI}=$ $0.469-0.993 ; P=0.046)$. This supports the theory that H. pylori infection, when present, leads to gastritis and reduces acid output, which is a protective action against variceal bleeding. Sakamoto et al., in their cross-sectional study, found that patients with $H$. pylori infection had a significantly lower risk of bleeding from varices compared to patients without H. pylori infection (odds ratio $=0.475 ; P=0.019$ ). ${ }^{4}$ Gastric acid is believed to be responsible for variceal rupture and bleeding. In the current study, among H. pylori-positive individuals, in whom PG I/II ratio correlates closely with gastric acid output, it was found that the median of the PG I/II ratio was significantly higher among patients with rebleeding than among those without it (2.9 versus $1.3 \mathrm{ng} / \mathrm{mL} ; P=0.023$ ). Among $H$. pylori negative individuals, in whom PG I correlates closely with gastric acid output, it was found that the median of PG I was significantly higher among patients with rebleeding compared to those without it (30.7 versus $14.4 \mathrm{ng} / \mathrm{mL} ; P<0.001)$. This shows that, both in the presence and absence of $H$. pylori infection, patients with rebleeding episodes had higher pepsinogen levels, probably reflecting more gastric acid output, compared to those who had no rebleeding.

The site of variceal bleeding was almost similar among patients positive or negative for $H$. pylori infection. Though gastric acid reflux into the lower oesophagus is a physiological phenomenon, in cases of cirrhotic patients, it is postulated that this refluxed gastric acid causes breaks in the epithelium covering the oesophageal varices, which in turn causes variceal rupture and triggers a bout of haematemesis. H. pylori, by causing chronic atrophic gastritis and reducing gastric acid output, in turn, reduces gastric acid reflux into the lower oesophagus and hence is protective against variceal rupture. This is supported by some previous studies, which have shown that long-term PPI therapy in patients with liver cirrhosis can reduce variceal bleeding rates probably due to the same mechanism..$^{21}$

The present study found no difference in the risk of development of hepatic encephalopathy between those with $H$. pylori infection and those without it. The prevalence of hepatic encephalopathy in the present study was relatively low. The total number of patients who had hepatic encephalopathy in the present study was 11 (6.9\%); seven patients who were $H$. pylori positive were found to have hepatic encephalopathy compared to four patients who were H. pylori negative. However, this difference was not statistically significant. Calvet et al. conducted a prospective study and found that $H$. pylori was not independently associated with the development of hepatic encephalopathy. ${ }^{12}$ The results of the present study are consistent with the aforementioned study probably because patients with only overt hepatic encephalopathy were included in both the studies. A systematic review of 20 studies by $\mathrm{Hu}$ et al. was conducted in China to determine the association between the risk of hepatic encephalopathy and that of $H$. pylori infection. ${ }^{22}$ The review found that the prevalence of $H$. pylori infection was higher in patients with hepatic encephalopathy than those without it. ${ }^{22}$ In the present study, the effect of $H$. pylori could have been masked by the lower prevalence of hepatic encephalopathy. 
The strengths of the present study are that it is one of a very small number of studies on the association between $H$. pylori infection and variceal bleeding and the only prospective study evaluating the association between $H$. pylori infection and variceal rebleeding. The limitations are that the study included only patients with overt hepatic encephalopathy, excluding those with minimal hepatic encephalopathy and subclinical hepatic encephalopathy, which could have resulted in the underdiagnosis of hepatic encephalopathy in the studied patients. The present study showed that H. pylori has an inverse relationship with episodes of rebleeding from oesophagogastric varices in cirrhotic patients with portal hypertension; hence, eradication of $H$. pylori may not be recommended routinely.

\section{Conclusion}

This prospective analytical study found that the rebleeding episodes were significantly less among those who had $H$. pylori infection compared to those without it. Compared to gastric varices, oesophageal varices were found to have a significantly lower risk of rebleeding. Location of the bleeding varices was not found to be significantly different between $H$. pylori positive and negative patients. Patients belonging to the Child-Pugh class B and C and those with grade 3/4 varices had higher rebleeding episodes. Irrespective of the $H$. pylori infection status, patients with rebleeding had higher levels of pepsinogen, indicating high gastric acid output. Furthermore, there was no difference in the level of serum pepsinogen between $H$. pylori positive and negative patients. The present study did not find an association between $H$. pylori infection and encephalopathy. $H$. pylori-infected patients were found to have significantly less rebleeding episodes, with no significant increase in the incidence of encephalopathy. Hence, routine $H$. pylori eradication may not be recommended for all cirrhotic patients with portal hypertension, as the present study showed that $H$. pylori was protective against variceal bleeding episodes. Consequently, eradication of $H$. pylori might precipitate variceal bleeding episodes and may only be considered for symptomatic $H$. pylori infections.

\section{AUTHORS' CONTRIBUTION}

SS and VK conceptualised and designed the study. SV was responsible for the data collection. SV and VB were responsible for the investigation. BG, EA, SM and VK contributed to the validation of the study. SM designed the methodology. SV, BG, EA, VK and TM were involved in data analysis and interpretation. SS, VK, VB and TM supervised the work. SV drafted the initial manuscript. SS, BG, EA, SM, VK, VB and TM were involved in drafting and revising the manuscript. All authors approved the final version of the manuscript.

\section{ACKNOWLEDGEMENT}

The authors would like to acknowledge the assistance of Dr Prem Kumar, Junior Resident, Department of Preventive and Social Medicine, Jawaharlal Institute of Postgraduate Medical Education and Research, Pondicherry, India, for the statistical analysis.

\section{CONFLICTS OF INTEREST}

The authors declare no conflicts of interest.

\section{FUNDING}

The study was funded by the intramural research grant offered by the Jawaharlal Institute of Postgraduate Medical Education and Research, Pondicherry, India.

\section{References}

1. Linz B, Balloux F, Moodley Y, Manica A, Liu H, Roumagnac P, et al. An African origin for the intimate association between humans and Helicobacter pylori. Nature 2007; 445:915-18. https://doi.org/10.1038/nature05562.

2. Mitchell HM. The epidemiology of Helicobacter pylori. Curr Top Microbiol Immunol 1999; 241:11-30. https://doi. org/10.1007/978-3-642-60013-5_2.

3. Roubaud Baudron C, Franceschi F, Salles N, Gasbarrini A. Extragastric diseases and Helicobacter pylori. Helicobacter 2013; 18:44-51. https://doi.org/10.1111/hel.12077.

4. Sakamoto Y, Oho K, Toyonaga A, Kumamoto M, Haruta T, Inoue $\mathrm{H}$, et al. Effect of Helicobacter pylori infection on esophagogastric variceal bleeding in patients with liver cirrhosis and portal hypertension. J Gastroenterol Hepatol 2013; 28:1444-9. https://doi.org/10.1111/jgh.12221.

5. Iijima K, Sekine H, Koike T, Imatani A, Ohara S, Shimosegawa T. Serum pepsinogen concentrations as a measure of gastric acid secretion in Helicobacter pylori-negative and -positive Japanese subjects. J Gastroenterol 2005; 40:938-44. https://doi. org/10.1007/s00535-005-1677-x.

6. Demirtürk L, Yazgan Y, zci O, Ozel M, Toğrol E, Gültepe M, et al. The effect of Helicobacter pylori eradication on gastric juice and blood ammonia concentrations and on visual evoked potentials in cirrhotics. Helicobacter 2001; 6:325-30. https:// doi.org/10.1046/j.1083-4389.2001.00039.x.

7. Kudo M, Zheng RQ, Kim SR, Okabe Y, Osaki Y, Iijima H, et al. Diagnostic accuracy of imaging for liver cirrhosis compared to histologically proven liver cirrhosis. A multicenter collaborative study. Intervirology 2008; 51:17-26. https://doi.org/10.1 159/000122595.

8. Das R, Sureshkumar S, Sreenath GS, Kate V. Sequential versus concomitant therapy for eradication of Helicobacter pylori in patients with perforated duodenal ulcer: A randomized trial. Saudi J Gastroenterol 2016; 22:309-15. https://doi.org/10.41 03/1319-3767.187605.

9. Laine LA, Nathwani RA, Naritoku W. The effect of GI bleeding on Helicobacter pylori diagnostic testing: A prospective study at the time of bleeding and 1 month later. Gastrointest Endosc 2005; 62:853-9. https://doi.org/10.1016/j.gie.2005.09.019. 
10. Mittal S, Trakroo S, Kate V, Jagdish S. Evaluation of the effect of presence of blood in the stomach on endoscopic diagnostic tests for Helicobacter pylori infection. Indian J Med Microbiol 2011; 29:379-82. https://doi.org/10.4103/0255-0857.90170.

11. Samloff IM. Cellular localization of group I pepsinogens in human gastric mucosa by immunofluorescence. Gastroenterology 1971; 61:185-8. https://doi.org/10.1016/ S0016-5085(19)33596-6.

12. Calvet X, Nogueras C, Roqué M, Sanfeliu I. Helicobacter pylori is not a risk factor for hepatic encephalopathy. Dig Liver Dis 2001; 33:414-19. https://doi.org/10.1016/s15908658(01)80013-x.

13. Batmanabane V, Kate V, Ananthakrishnan N. Prevalence of Helicobacter pylori in patients with portal hypertensive gastropathy--A study from south India. Med Sci Monit 2004; 10:133-6

14. Villalan R, Maroju NK, Kate V, Ananthakrishnan N. Is Helicobacter pylori eradication indicated in cirrhotic patients with peptic ulcer disease? Trop Gastroenterol 2006; 27:166-8.

15. Kate V, Ananthakrishnan N, Ratnakar C, Badrinath S. Anti - H pylori IgG seroprevalence rates in asymptomatic children and adults from South India. Indian J Med Microbiol 2001; 19:20-5. https://doi.org/10.1016/S0255-0857(21)03367-3.

16. Prasad S, Mathan M, Chandy G, Rajan DP, Venkateswaran S, Ramakrishna BS, et al. Prevalence of Helicobacter pylori in southern Indian controls and patients with gastroduodenal disease. J Gastroenterol Hepatol 1994; 9:501-6. https://doi. org/10.1111/j.1440-1746.1994.tb01281.x.
17. Costable NJ, Greenwald DA. Upper gastrointestinal bleeding. Clin Geriatr Med 2021; 37:155-72. https://doi.org/10.1016/j. cger.2020.09.001

18. Elsebaey MA, Tawfik MA, Elshweikh SA, Negm MS, Elnaggar $\mathrm{MH}$, Alghazaly GM, et al. Impact of Helicobacter pylori infection on gastric variceal bleeding among patients with liver cirrhosis. Gastroenterol Res Pract 2019; 2019:6529420. https:// doi.org/10.1155/2019/6529420.

19. Feng H, Zhou X, Zhang G. Association between cirrhosis and Helicobacter pylori infection: A meta-analysis. Eur J Gastroenterol Hepatol 2014; 26:1309-19. https://doi. org/10.1097/MEG.0000000000000220.

20. Pogorzelska J, Łapińska M, Kalinowska A, Łapiński TW, Flisiak R. Helicobacter pylori infection among patients with liver cirrhosis. Eur J Gastroenterol Hepatol 2017; 29:1161-5. https:// doi.org/10.1097/MEG.0000000000000928.

21. Lin L, Cui B, Deng Y, Jiang X, Liu W, Sun C. The efficacy of proton pump inhibitor in cirrhotics with variceal bleeding: a systemic review and meta-analysis. Digestion 2021; 102:11727. https://doi.org/10.1159/000505059.

22. Hu BL, Wang HY, Yang GY. Association of Helicobacter pylori infection with hepatic encephalopathy risk: A systematic review. Clin Res Hepatol Gastroenterol 2013; 37:619-25. https://doi.org/10.1016/j.clinre.2013.05.004. 